\title{
Mandibular Periosteal (Juxtacortical) Chondrosarcoma
}

\author{
Elisângela Maria Cunha COSTA ${ }^{1}$ \\ Bárbara Lima LUCAS ${ }^{1}$ \\ Mariana Reis SILVA ${ }^{1}$ \\ Renata Hinhug VILARINHO ${ }^{1}$ \\ Paulo Rogério de FARIA ${ }^{2}$ \\ Adriano Mota LOYOLA ${ }^{1}$
}

\begin{abstract}
${ }^{1}$ Laboratory of Oral Pathology, Dental School, Federal University of Uberlândia, Uberlândia, MG, Brazil ${ }^{2}$ Department of Morphology, Institute of Biomedical, Federal University of Uberlândia, Uberlândia, MG, Brazil
\end{abstract}

\begin{abstract}
Periosteal (juxtacortical) chondrosarcoma (PC) is a well-differentiated malignant cartilage-forming tumor arising from the external bone surface, especially in long bones. The therapy of choice is en-bloc resection and, in general, its prognosis is good. This paper reports a rare case of PC affecting the mandible of a 41-year-old man. The lesion presented as a slow-growing-painless swelling that lasted 2 months. Computed tomography scan showed a tumoral mass arising from the external bone surface, extending into the adjacent soft tissue presenting patchy regions of popcorn-like calcifications. A final diagnosis of PC (grade II) was rendered after biopsy. Hemimandibulectomy was undertaken followed by complementary radiotherapy with 70 Gy. Although no episodes of recurrence or metastasis had been noticed after 18 months of follow-up, the patient died and causa mortis could not be established.
\end{abstract}

Key Words: chondrosarcoma, periosteal chondrosarcoma, mandible, jaws, bone pathology.

\section{INTRODUCTION}

Chondrosarcomas are malignant tumor characterized by cartilage production. Despite of their common occurrence in long bones as intramedullary lesions, $1-3 \%$ of them affect the head and neck region mainly jaw bones (1-4). In spite of their aggressive local behavior and poor prognosis, these tumors have been reported as being of low metastatic potential $(1,2)$. A less common subtype of malignant tumor of cartilage-forming tissues is the periosteal (juxtacortical) chondrosarcoma (PC). This distinct entity typically manifests as a slow-growingpainless lump from the external bone surface (5-7). It is usually diagnosed as a well-differentiated lesion (grade I) and presents a less aggressive course (8-10). So far, only one case of PC in the head and neck region affecting the lingual plate of the mandibular body has been published in the English-language literature (11).
This paper describes the second case of $\mathrm{PC}$ arising in the mandible of a male adult patient.

\section{CASE REPORT}

A 41-year-old Caucasian man was referred to the dental clinic of a Public Health Center complaining of a painless lump on the left side of his mandible that had lasted for 2 months. He was otherwise healthy, but reported that he had stopped smoking 10 years before, after having smoked for 27 years. The medical history was not contributory. Upon intraoral examination an ulcerated, fixed, non-tender erythematous mass was noted on the left mandible extending from the second premolar to the third molar region. Although the adjacent first and second molars were apparently vital, both teeth exhibited moderate mobility (Fig. 1). Upon neck examination, no cervical lymphadenopathy was apparent. 
Panoramic radiography showed a discrete radiolucent area with ill-defined limits sited in the bifurcation of the first and second molars, coupled with a vertical periodontal bone loss as well as apparent widening of the periodontal ligament space related to distal root of the first molar. A slight bone rarefaction area mixed with discrete ill-defined "spotty densities" could be seen near the second molar (Fig. 2). As these findings could not immediately be associated with the presence of the large mandibular swelling, the patient was referred to an Oncology Center 1 month after the first consultation where a computed tomography (CT) scan was done. The images revealed a predominantly well-circumscribed hypointense soft tissue lesion facing the buccal cortex of the left mandible and growing into the adjacent soft tissue. Within the tumoral area, a lot of patchy hyperintense (calcified) structures could be noted. The buccal and lingual cortices were notably intact and slight sclerosis of the buccal cortex in the molar region was observed (Fig. 3). Furthermore, no kind of alterations in the parotid, carotid and masticatory spaces could be noted. Based on this, a hypothesis of periosteal osteosarcoma was raised.

Thereafter, an incisional biopsy under local anesthesia was performed and the fragments were sent to the pathologist. Under macroscopic examination,

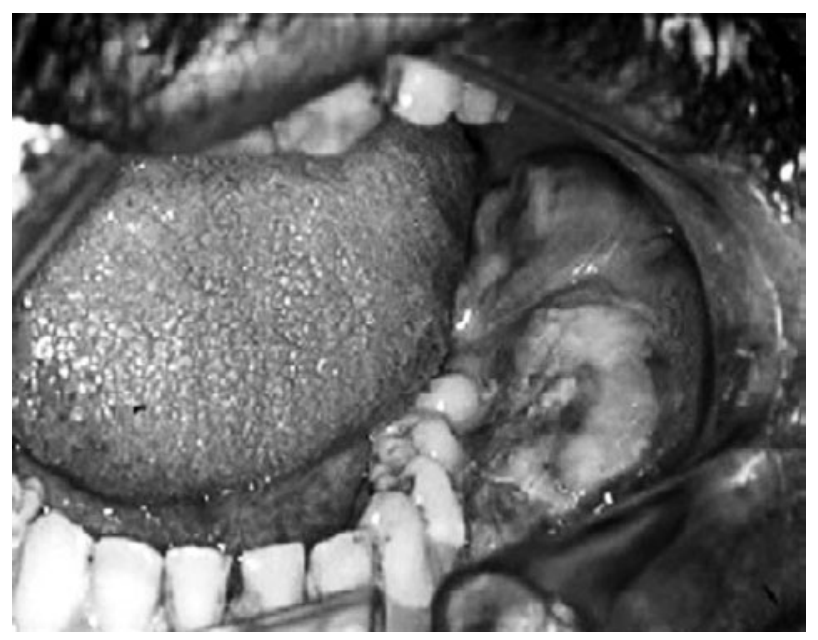

Figure 1. Clinical aspects of the mandibular periosteal (juxtacortical) chondrosarcoma. An ulcerated, firm, fixed, nontender erythematous swelling can be observed on the buccal aspect of the left mandible extending from the second premolar region to the third molar region. The tumor is causing apparent dislodgment of the left first molar. the specimens were constituted of 2 somewhat hard, tan-colored tissue fragments, without any particular morphological aspects. Microscopically, the tumor presented a lobulated neoplastic hyaline cartilage separated by fibrous bands and focal myxoid change. Aggregates of oval and fusiform undifferentiated cells were seen in the periphery of the lobules. Cartilaginous differentiation with enchondral bone formation was evident in the centre of the tumoral lobules, whose cells presented of mild to moderate grade of atypia, including multiple and/or enlarged grotesque nuclei. Mitoses were rare. Moreover, areas of calcification could be seen throughout the neoplastic tissue. Nevertheless, no area of malignant osteoid with or without included atypical cells was found (Fig. 4). These histopathological aspects were conclusive for moderately differentiated chondrosarcoma (grade II).

Left hemimandibulectomy and hemipelvectomy with sacrifice of the inferior alveolar nerve were done. All surgical specimens were sent for histopathological analyses. Grossly, the lesion extended from the second premolar to the third molar on the same side. On the cut surface, an inconspicuous inner limit leaning on, but no apparent destruction or invasion of the buccal cortex was observed. Three triangular sections were taken away from the tumoral periphery for microscopic examination. The final diagnosis was chondrosarcoma (grade

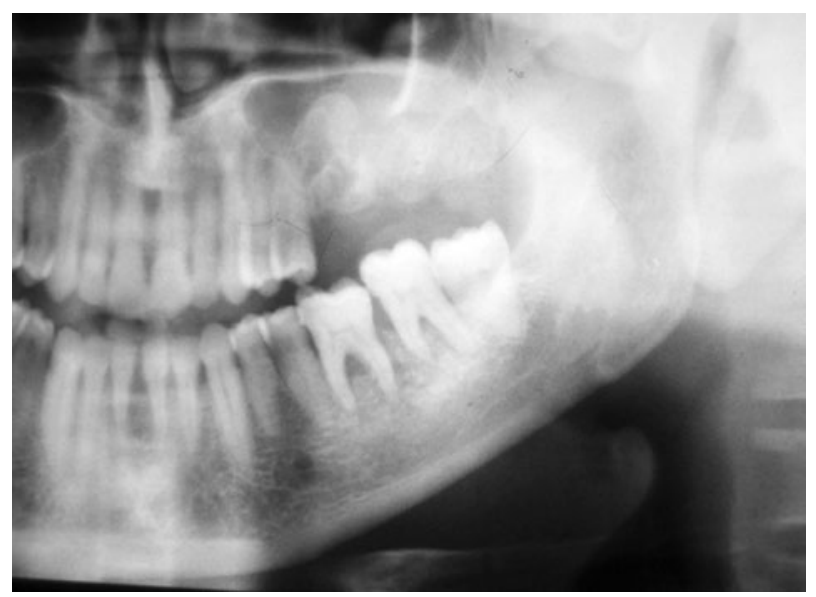

Figure 2. Partial view of the panoramic radiograph showing a discrete radiolucent area with ill-defined limits sited in the bifurcation of the first and second molars. Vertical alveolar bone loss in the distal region of the first molar, extending to the periradicular bone of the mesial root of the second molar can also be noted. Discrete area of spotty densities is also present near the mesial root of the second molar. 
II). As complementary treatment, a course of adjuvant radiotherapy with 70 Gy was completed in 7 months. Thereafter, a metastatic work-up was started, which included roentgenograms of the cranium, liver, axial and appendicular skeleton. Follow-up regimen consisted of a thorough head and neck examination every 4 months coupled with one chest radiography.

During the radiation therapy his family reported that patient presented hearing loss, which was admitted as sequelae of the treatment. Clinical and imaginologic evaluations with 3-month intervals were made. Although no evidence of tumor recurrence was observed during 18 months of follow up, the patient died 2 months after the last consultation, but no data on the causa mortis could be established.

\section{DISCUSSION}

Long bones PC account for less than $2 \%$ of all chrondrosarcomas. They typically manifest as slowgrowing-painless lumps arising from the surface of bone without medullar commitment. They are twice more frequent in men and present over a wide age range (from 15 to 63 years) $(5,7,12,13)$. Using the grading system applied for conventional intramedullary chrondrosarcoma, long bones PC are categorized as tumors of grade I or II and with low or no tendency to metastasize (6). Up to now, only one case affecting the mandible has recently been reported (11).

Since this lesion is rare in the head and neck region, little clinicopathologic information on it could be obtained from the literature. Because of this, clinical and imaginologic aspects of the present case will be discussed in the light of current knowledge on long bones PC and the unique case in head and neck described by Van Damme et al. (11). Our patient presented a firm asymptomatic swelling on the left posterior mandible, which was confirmed by the CT scan. Moreover, CT scan clearly demonstrated the tumor emerging from the cortical bone and absence of any cortical injury. Instead, the underlying cortex presented only a slight sclerotic reaction $(6,13)$. Furthermore, an absence of medullar bone involvement by the tumor could also be certified during gross ex-
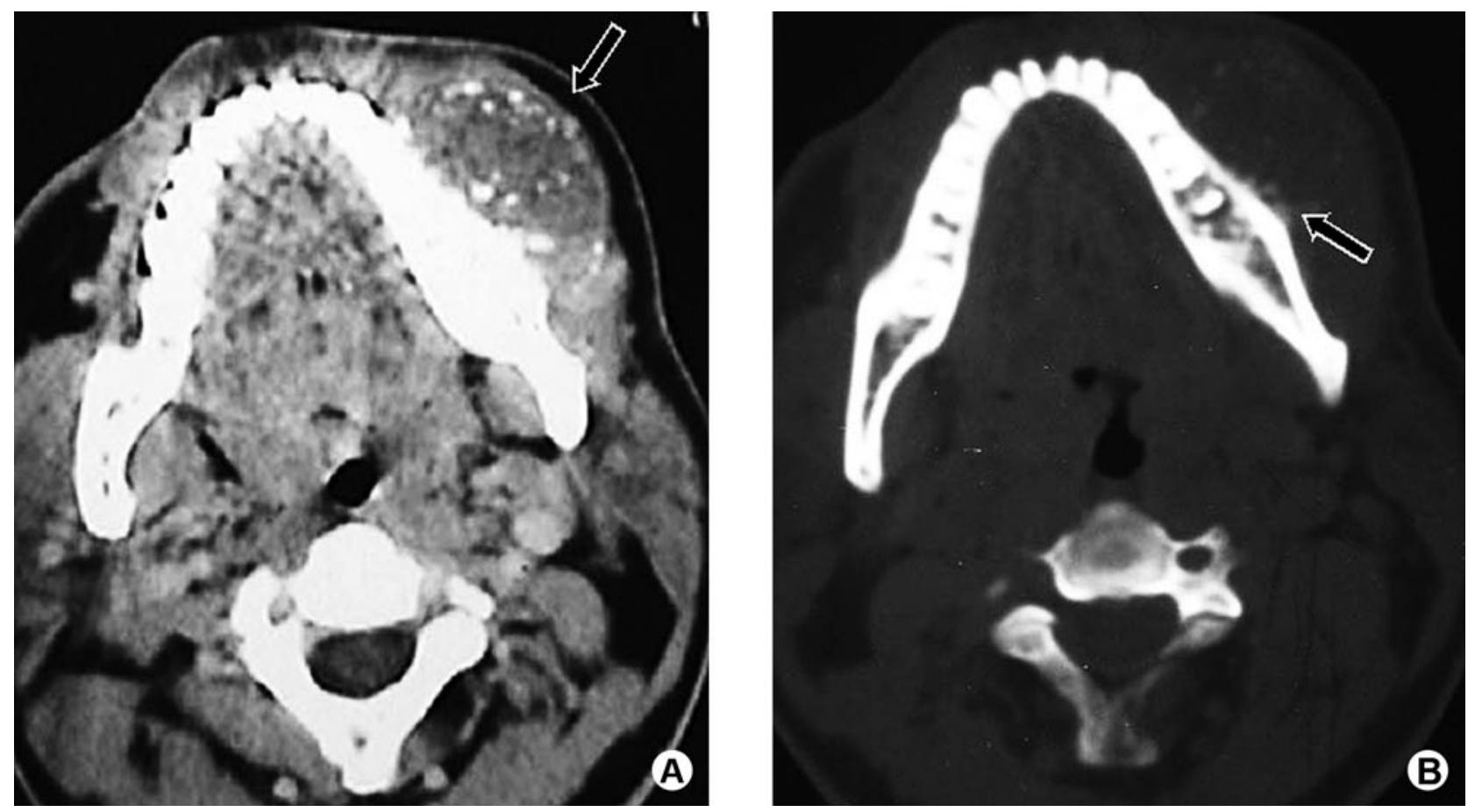

Figure 3. CT scan from axial views of the lesion. A = Well-circumscribed well-delimited ovoid hypodense image with many patchy hyperintense structures (radiopaque) inside it (soft tissue window) (arrow). B= Both the cortical bone plates are notable. Slight signs of sclerosis on the buccal cortex could be noted (hard tissue window) (arrow). 
amination (not documented), suggesting a periosteal localization for it. As demonstrated by Van Damme et al. (11), macroscopic and imaging aspects are very important to establish a diagnosis of PC. However, as described to long bones PC and observed in the present case, this lesion may present a well-delimited tumoral front in the mucosal soft tissue on CT scan, reflecting the periosteal dislodgment from the cortical plate that
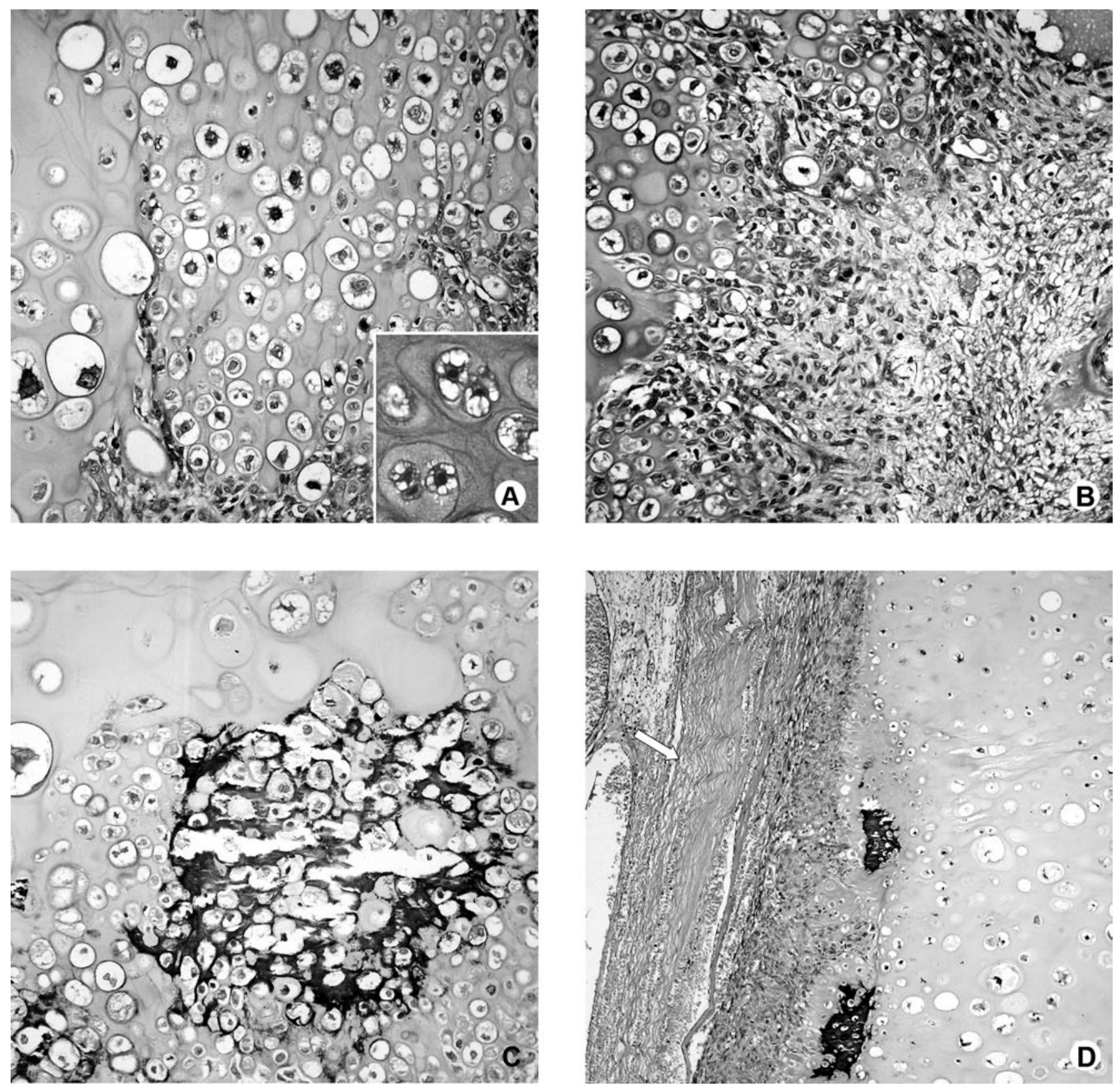

Figure 4. Histological aspects of the PC: A) malignant chondroblast showing a moderate grade of atypia such as anisocytosis, anisocariosis and nuclear hyperchromatism (hematoxylin-eosin, original magnification $\times 200$ ). Insert: occasional binucleated cells could be observed (hematoxylin-eosin, original magnification $\times 400$ ); B) myxoid areas (center) were seen with interposed lobules of malignant chondroid tissue through the lesion (hematoxylin-eosin, original magnification $\times 200$ ); C) Foci of enchondral calcifications were found sparsely distributed within the tumoral lobules (hematoxylin-eosin, original magnification $\times 200$ ); D) A well-defined capsule (arrow) could be noted around the tumor (hematoxylin-eosin, original magnification $\times 100$ ). 
imparted well-defined limits to the neoplastic growth. This imaging finding was described by Van Damme et al. (11) as well. Moreover, the presence of typical popcorn-like calcifications (hyperintense patches) sited in the center of the image completed the classic imaging aspects described to long bones PC.

In spite of this, some points of the present case could cast doubts on its periosteal origin, which deserve complementary discussion. The presence of a lingual dental displacement, mobility of the second molar and irregular pattern of bone loss with altered trabecular morphology demonstrated by radiographic image could suggest intramedullary origin or, at least, an intramedullary extension of the tumor. In fact, widening of the periodontal ligament space and tooth mobility have been reported associated to the mandible chondrosarcomas, while erosion, saucerization, cortical destruction and medullar invasion has been reported for long bones PC $(6,12-14)$. Notwithstanding, some evidences contradicted both the medullary origin and medullary commitment for this tumor. Firstly, as can be observed in Figure 2, alveolar bone loss in the left premolar and molar regions was similar to bone loss seen in a periodontal disease. Extensive periodontal bone loss due to a generalized periodontal disease was also found in other sites, as seen in the incisive maxillary region. Therefore, it is possible that the tumor growing on the cortical plate could have induced pressure on and displacement of the teeth, as detected both clinically and radiographically. Further, it is also important to mention that the medullary cavity was normal and no cortical rupture or defect was found by CT scan. Intramedullary chondrosarcoma usually breaks the cortex and invades the surrounding soft tissues (6) and these findings were not seen on imagenological examination in the present case.

Histologically, PC is similar to the conventional chondrosarcomas. The periphery of the lobules contains more roundish or spindle shaped undifferentiated cells with little intercellular matrix. Towards the center of the lobules, cartilaginous differentiation is evident, with more abundant hyaline matrix. In most cases, cellular atypia and presence of one or more plump, sometimes monstrous or bizarre nuclei, indicating a moderate to high-grade malignancy can be observed in these areas. All tumors present calcification zones, which are generally accompanied by enchondral ossifications occurring perpendicularly to the underlying cortex $(15,16)$.
A controversial point in the literature is whether PC really is an entity distinct from periosteal osteosarcoma (10). Chondrosarcoma, including the periosteal type, contains no malignant osteoid or bone tumoral formation. Moreover, in long bones they present less aggressive, painful and run a slower course than the periosteal osteosarcomas (15). Radiographically, radiopaque striations (spicules) perpendicular to the relatively normal underlying cortex, a common feature of periosteal osteosarcoma, are absent in almost all cases of PC. In our case, the presence of a well-defined soft tissue with spotty densities reinforces the diagnosis of PC $(4,6,7,10,15,16)$.

Treatment of choice for long bones PC is enbloc resection with a wide margin of normal soft tissue and bone. The use of radiotherapy in the treatment of chrondrosarcomas is a contentious question in the literature and has been applied as a complementary therapy in cases of high grade tumor to control unresectable tumors as those sited on the base of skull. However, for well and moderate differentiated lesions as well as PC radiotherapy has been considered unnecessary. Therefore, the use of radiotherapy in the present case might be argued, since it is an unusual therapeutic procedure for PC. However, it was indicated due the size of the tumor and soft tissue invasion by the lesion. The prognoses for the long bones PC seem to be much better than central chondrosarcomas of similar grade of malignancy and the majority is diagnosed as grade I or II lesion. Metastases are uncommon, even in cases of medullary involvement (6-10). However, recurrences and distant metastasis (lung, brain and lymph node) for long bones $\mathrm{PC}$ have been reported in cases of inadequate primary treatment and for those tumors with presence of tumoral dedifferentiation (grade II and III) $(5,9,10,13)$. In the case described by Van Damme et al. (11), a tenyear tumor-free follow-up was verified which pointed out an indolent behavior for the tumor. Unfortunately, in our case, the follow-up was only of 18 months. At that time, no clinical evidence of aggressive tumoral behavior could be noted.

To date, there are no data to support a different biological behavior of head and neck PC compared with long bones PC $(2,4)$. Therefore, given the rarity of PC, multicenter trials will be required to develop standardized protocols to distinguish this lesion from other surface tumors, and to evaluate its behavior when it occurs in the head and neck region. 


\section{RESUMO}

Condrossarcoma (juxtacortical) periosteal (CP) é um tumor maligno produtor de cartilagem bem diferenciado que normalmente surge na superfície externa dos ossos longos. O tratamento de escolha para esse tumor é a ressecção em bloco e, em geral, apresenta um prognóstico bom. Nesse trabalho, nós apresentamos um caso raro de CP afetando a mandíbula de um homem de 41 anos de idade. A lesão apresentava um crescimento lento e indolor de 2 meses de evolução. A tomografia computadorizada revelou a presença de uma massa tumoral surgindo na superfície externa do osso mandibular exibindo agregados de tecido calcificado no seu interior e que se estendia para os tecidos moles adjacentes. Depois de realizada uma biópsia, um diagnóstico final de CP (grau II) foi estabelecido. O tratamento de escolha foi hemimandibulectomia seguida por radioterapia complementar na dose de 70 Gy. Embora nenhum episódio de recorrência ou metástase tenha sido noticiado após 18 meses de acompanhamento, o paciente morreu e a causa mortis não pôde ser determinada.

\section{ACKNOWLEDGEMENTS}

The authors would like to thank the funding agencies CNPq and FAPEMIG for financial support.

\section{REFERENCES}

1. Sammartino G, Marenzi G, Howard CM, Minimo C, Trosino O, Califano L, et al.. Chondrosarcoma of the jaw: a closer look at its management. J Oral Maxillofac Surg 2008;66:2349-2355.

2. Tien N, Chaisuparat R, Fernandes R, Sarlani E, Papadimitriou JC, Ord RA, et al.. Mesenchymal chondrosarcoma of the maxilla: case report and literature review. J Oral Maxillofac Surg 2007;65:12601266.

3. Prado FO, Nishimoto IN, Perez DE, Kowalski LP, Lopes MA. Head and neck chondrosarcoma: analysis of 16 cases. Br J Oral Maxillofac Surg 2009;47:555-557.

4. Panda NK, Jain A, Reddy CEE. Osteosarcoma and chondrosarcoma of the maxilla. Br J Oral and Maxillofac Surg 2003;41:329333.
5. Putti TC, Kahn LB, Aprin H. Periosteal chondrosarcoma: a case report and review of the literature. Arch Pathol Lab Med 1997; 121:70-74

6. Hatano H, Ogose A, Hotta T, Otsuka H, Takahashi HE. Periosteal chondrosarcoma invading the medullary cavity. Skeletal Radiol 1997;26:375-378.

7. Kumta SM, Griffith JF, Chow LT, Leung PC. Primary juxtacortical chondrosarcoma dedifferentiating after 20 years. Skeletal Radiol 1998;27:569-573.

8. Kenan S, Abdelwahab IF, Klein MJ, Hermann G, Lewis MM Lesions of juxtacortical origin (surface lesions of bone). Skeletal Radiol 1993;22:337-357.

9. Matsumoto K, Hukuda S, Ishizawa M, Saruhashi Y, Okabe H, Asano Y. Parosteal (juxtacortical) chondrosarcoma of the humerus associated with regional lymph node metastasis. A case report. Clin Orthop Relat Res 1993;290:168-173.

10. Vanel D, DE Paolis M, Monti C, Mercuri M, Picci P. Radiological features of 24 periosteal chondrosarcomas. Skeletal Radiol 2001;30:208-212.

11. Van Damme PA, DE Wilde PC, Koot RA, Bruaset I, Slootweg PJ, Ruiter DJ. Juxtacortical chondrosarcoma of the mandible: report of a unique case and review of the literature. Int Oral Maxillofac Surg 2005;34:94-98.

12. Mena JC, Kaakaji Y, Chalpin DB, Nietzschman HR. Case 1: Juxtacortical chondrosarcoma. AJR Am J Roentgenol 1998;171:864 865.

13. Mitchell A, Rudan JR, Fenton PV. Juxtacortical dedifferentiated chondrosarcoma from a primary periosteal chondrosarcoma. Mod Pathol 1996;9:279-283.

14. Vencio EF, Reeve CM, Unni KK, Nascimento AG. Mesenchymal chondrosarcoma of the jaw bones: clinicopathologic study of 19 cases. Cancer 1998;82:2350-2355.

15. Bertoni F, Boriani S, Laus M, Campanacci M. Periosteal chondrosarcoma and periosteal osteosarcoma. Two distinct entities. J Bone Joint Surg Br 1982;64:370-376.

16. Tossato PS, Pereira, AC, Cavalcanti WGP. Osteosarcoma and chondrosarcoma radiographic differentiation by means of computed tomography. Pesqui Odontol Bras 2002;16:69-76.

Accepted October 13, 2009 